\title{
Aproximación antropológica a la seguridad en las sociedades complejas
}

\section{Anthropological approximation to safety in complex societies}

\begin{abstract}
Fina Anton ${ }^{1}$
fmanton@um.es

\section{Resumen}

La seguridad no es una mera estrategia, es una necesidad que se traduce en un sentimiento, una emoción que rememora el significado latino del término, sine curas (sin ansiedad). A partir de esta sensación, las personas confieren sentido a cada una de las acciones que desarrollan tanto en el ámbito privado como público y tanto en el entorno individual como colectivo. Desde este planteamiento, mi aportación pretende analizar antropológicamente cómo la percepción de la seguridad se relaciona con las modificaciones que se están incorporando al complejo cronotopo y a través del análisis de los módulos de cultura podremos comprender la situación actual en las sociedades complejas.
\end{abstract}

\section{Palabras claves}

Cultura, antropología, seguridad, inseguridad, emociones.

\section{Abstract}

Security is not just a strategy, but a need that results in a feeling from which people give meaning to each one of the actions that takes place both in the private and in the public fields, both individually and collectively. From this perspective, my contribution tries to analyse anthropologically how this concept relates with the modules of culture and so understand the current situation in complex societies.

\section{Keywords}

Culture, anthropology, security, insecurity, emotions.

Forma sugerida de citar: ANTON, Fina (2013). “Aproximación antropológica a la seguridad”. En: Universitas, XI (19), julio-diciembre, p.73-100. Quito: Editorial Abya Yala/Universidad Politécnica Salesiana.

1 Profesora de Antropología Social de la Universidad de Murcia-España. 


\section{Introducción}

Tras la Segunda Guerra Mundial se estableció un mundo dividido como un tablero de ajedrez con solo dos jugadores: Estados Unidos y la Unión Soviética. Durante el período de la Guerra Fría, el estudio de la seguridad se realizó desde una perspectiva militar-estratégica-hegemónica particular, a la que se unió una visión política específica, en la que la amenaza militar directa tenía un rostro identificable y una ideología política antagónica. La caída del Muro de Berlín en 1989, la implosión de la Unión Soviética, la emergencia de otras economías (Brasil, Rusia, India y China) y el terrorismo internacional, obligó a la reconstrucción de las relaciones internacionales europeas y mundiales, y supuso que la construcción maniquea del mundo perdiera toda aplicabilidad. Como consecuencia de esto asistimos al agotamiento de las grandes ideologías, la inauguración de un nuevo orden mundial, el surgimiento de narrativas que vaticinan el fin de la historia en nombre de un mundo utópico liberal universal y la visión apocalíptica de un choque de las civilizaciones. Todos estos discursos eran política y académicamente certificados como ciencia y pretendían volver a trazar nuevas líneas de demarcación entre "nosotros" y los "otros". La seguridad era un tema que interesaba como estructura que permite establecer relaciones de equilibrio entre las grandes potencias. Los investigadores en ciencias políticas $\mathrm{y}$ en relaciones internacionales aportaron una serie de narrativas que sustentaron los discursos sobre seguridad de políticos y militares (Antón Hurtado y Ercolani, 2013). El reduccionismo positivista imperante supuso la parcelación y la focalización de los resultados de la investigación, y aunque la asunción del mismo haya supuesto un avance científico y tecnológico sin precedentes, también ha provocado la desorientación de las ciencias humanas y el alejamiento de los intereses y las inquietudes de la mayoría de las personas.

Los atentados a las Torres Gemelas el 11 de septiembre de 2001 visibilizaron la importancia que la seguridad tiene en el desarrollo de nuestras vidas y fueron muchas las disciplinas que se interesaron por ella, pero este tratamiento multidisciplinar, lejos de esclarecer el concepto de seguridad, lo ha convertido en un término ambiguo. De ahí la conveniencia de incorporar la antropología. 


\section{La seguridad como emoción}

La seguridad es un tema poliédrico que ha estado presente en la vida de los seres humanos desde los albores de la especie. Estamos ante una aspiración universal que ha acompañado a la humanidad en todas sus manifestaciones culturales y a cada persona desde el momento de su nacimiento, ya que la seguridad emocional que los padres le ofrecen a sus hijos les permite desarrollar en mayor medida su curiosidad y capacidades exploratorias. Vivir en un entorno en el que las personas puedan sentirse seguras es la máxima garantía que podemos tener para llevar a cabo un proyecto de vida satisfactorio. Este proyecto vital no se planifica de forma aislada, sino en clara armonía con el resto de la comunidad de la que formamos parte, con la que compartimos el sentido que damos a nuestra vida sobre la base de una seguridad que, en tanto sentimiento, nos cohesiona y relaja, y nos permite, desde la confianza sobre la que se sustenta, disfrutar de los bienes que nos ofrece el territorio que compartimos.

Para justificar la relevancia que nuestras aportaciones disciplinares pueden ofrecer a los estudios críticos de seguridad, asumimos la definición de antropología propuesta por Álvarez Munárriz (2011a: 425), que la considera el estudio de la naturaleza y el sentido del hombre con categorías específicas cuyo eje central consiste en, a través de la naturaleza, dilucidar el problema de la unidad humana, y a través del sentido de lo humano, analizando el comportamiento humano y los productos del hombre, llegar a explicar la diversidad humana. Esta aproximación disciplinar es especialmente fecunda en un momento cuando, como dice Alain Tourain "la déglobalisation ne fait que commencer" (2011: 81).

La fundamentación teórica asumida al amparo del positivismo inhabilita a las ciencias sociales para explicar los sentimientos y las emociones que están presentas en toda actividad humana. Sorprende que las ciencias sociales, en el transcurso de su "positivización" para alcanzar mayor reconocimiento y eficiencia prescriptiva, empiecen a desligarse de su fundamentación filosófica en muchos ámbitos, excepto en el que se refiere a lo emocional, donde la tradición filosófica occidental asume, del judeocristianismo y el cartesianismo la devaluación del mismo por considerarlo próximo a lo visceral y lo pasional, ambos, instintos "bajos" que refuerzan lo corporal frente a lo mental (Shilling y Mellor, 1996). La dicotomía cultura-mente se resuelve asumiendo 
que tanto las emociones como los sentidos oscurecen la razón. Max Weber sitúa a las emociones en el ámbito de lo irracional, tratándose por tanto, de una desviación o perturbación de la racionalidad (Favret-Saada, 1994)

El racionalismo refuerza el poder de la razón, lo que le facilita a la antropología social la asunción de los dos paradigmas hegemónicos de finales del siglo XIX y principios del XX, el positivismo y el evolucionismo. El análisis de la racionalidad de los comportamientos humanos es más compatible con la mecánica cuántica de Einstein y el principio de indeterminación de Heisenberg, porque se limita a ofrecer definiciones operativas y funcionales, lo que resulta claramente incompleto, como reconoció el propio Einstein al afirmar que "es la teoría la que decide lo que nosotros observamos", dejando fuera el análisis de los sentimientos y las emociones (Chudnovsky y Tejada, 2011: 206). La concesión al evolucionismo vendría de la consideración de las sociedades occidentales como las más racionales y, por tanto, las más evolucionadas; de ahí que el propio Durkheim (1992), que reconoce la importancia de lo emocional en la configuración del grupo y el establecimiento de vínculos, entendiera el progreso como la depuración de los afectos, los cuales estarían ligados a una mentalidad primitiva.

La antropología social como saber global que asume una aproximación holística en sus investigaciones (Lévi-Strauss, 2011: 37) debe analizar el entorno emocional en el que se desenvuelven la vida las personas. Apelo a lo dicho por Marcel Mauss (1991) sobre la necesidad de construir la unidad de la experiencia humana: el cuerpo y el espíritu, el sentimiento y la razón, el hombre y la mujer, el adulto y el niño y, sobre todo, combinar la unidad de lo universal con la diversidad de las situaciones sociales y culturales. En la misma línea, Durkheim y Mauss (1963) coinciden en afirmar que todo proceso humano es socialmente mediado, experimentalmente vivido, y esto es común a todas las culturas.

Asumir la exigencia epistemológica de un saber global y de estudiar al hombre como un todo, presupone una investigación documental interdisciplinar, tanto audiovisual como escrita, que pide al antropólogo la aproximación a investigaciones tan diferentes de la nuestra como la seguridad alimentaria, seguridad energética, las ciencias neurocognitivas, las ciencias jurídicas, etc. Todo ello centrado en el análisis que nos ocupa, en el ámbito de los estudios 
críticos de seguridad asumidos por la estrategia militar y la nueva política económica global.

Esta aproximación holística permite asumir el modelo integral de la seguridad propuesto por Álvarez Munárriz (2013) en el que se analiza al individuo con una clara referencia 1) a las emociones, especialmente al sentimiento de seguridad, 2) a la sociedad cuya organización debe articular una serie de normas e instituciones que de manera racional garanticen la vida de las personas y sus derechos 3) a la cultura, en cuya pertenencia encuentran los individuos el arraigo que les identifica con el conjunto de creencias y valores compartidos y que confieren sentido a su propia existencia y a la de su comunidad y 3 ) todo ello referido a un contexto geopolítico, en el que, como dice Deleuze y Parnet (1997: 71) "los poderes tienen más necesidad de angustiarnos que de reprimirnos". En el ámbito de la antropología de las Emociones se plantea como necesario analizar antropológicamente la seguridad como sentimiento que se construye culturalmente en estrecha relación entre el individuo y su comunidad, sin olvidar que conciencia y emoción son dimensiones de un sistema dinámico que interactúa con el entorno y se manifiesta en determinados comportamientos (Yuri y Mikko, 2005). No se puede hablar de seguridad institucional, sin analizar la percepción social que se tiene o no de ella, la sensación de vulnerabilidad, inseguridad y desconfianza que podemos constatar a través del trabajo de campo. Haciendo uso de diferentes técnicas etnográficas conseguimos aproximarnos a los modos de ser, pensar y actuar de nuestros informantes, acercándonos en la medida de lo posible a la perspectiva EMIC de la investigación. De ahí que se haya podido decir que lo nuestro es el trabajo de campo (Lisón, 2012: 13). La antropología asume esa perspectiva EMIC, mientras los estudios estratégicos de seguridad adoptarían la ETIC.

Franz Boas (filósofo, matemático y astrónomo) encabezó una corriente antropológica que criticó el evolucionismo y dio lugar a diferentes tendencias como: el relativismo cultural, el particularismo histórico, la escuela norteamericana, la escuela de cultura y personalidad y el culturalismo. Boas sintetizó los principios básicos del romanticismo alemán de la primera mitad del siglo XIX, de la contrailustración y del historicismo. La evolución del "culturalismo" dio lugar a tres variantes, el formalismo, la teoría de la aculturación y la teoría de la modernización, que pretenden la fusión de antropología, psicología y socio- 
logía, mediante los estudios de cultura y personalidad. Su preocupación básica consistía en explicitar los mecanismos mediante los que la cultura determina al individuo y a la sociedad. Ruth Benedict, en tanto que precursora de la antropología de las emociones, en su obra El crisantemo y la espada (1974) distingue entre pueblos con culturas de la vergüenza (los griegos clásicos y la mayoría de los pueblos indígenas americanos) y los pueblos de culturas de la culpa (las sociedades que asumieron el cristianismo). Peristiany (1968) estudia la cultura del honor como cultura híbrida representativa de la zona mediterránea, en la que se combina el sentimiento de culpa, inculcado por le cristianismo, con el de vergüenza, heredado de los árabes, para los que la reprobación de unos hechos no está en los hechos mismos, sino en que salgan a la luz y se hagan públicos.

Las emociones son una expresión del binomio que nos conforma como especie humana, que no es sino la combinación entre naturaleza y cultura. Son mecanismos biológicos instintivos que se sustentan en procesos neuroquímicos y neurofisiológicos, que integrados en nuestro sistema cognitivo "dan color a nuestra vida y nos ayudan a afrontar las dos tareas fundamentales de la existencia: buscar el placer y evitar el dolor" (Kandel, 2013: 356). Arsuaga y MartínLoeches (2013: 278), por su parte, consideran que "la mente del ser humano actual se explica en gran medida por la confluencia de dos factores: el emocional, por ser la mente de un mamífero, y el social, por ser la de un primate".

Los sentimientos son manifestaciones de las gestión cultural de las emociones, o en palabras de Fericgla "las emociones culturalmente codificadas" (2012), a lo que Freud (1972) añade la influencia que estas tienen en la capacidad de actuación racional de los seres humanos, hasta tal punto que la conciencia habría evolucionado porque los organismos dotados de ella podían "sentir" las emociones. Con esta afirmación, Freud se posiciona frente a la tradición filosófica racionalista, iniciada por Demócrito, en la época griega, seguida por Kant en el siglo XVIII y que permanece vigente hasta el momento, según la cual la emoción entorpece a la razón. A través de su investigación clínica, el fundador del psicoanálisis descubrió que las emociones, lejos de entorpecer nuestras decisiones, las favorecen y nos ayudan a evitar el peligro y a aproximarnos a posibles fuentes de placer: "no se trata de una reacción puramente mental, sino somática, pues implica a todo el cuerpo del sujeto de la acción" (De Pina-Cabral, 2003: 98). Y el hecho de sentirlas de manera consciente su- 
pone centrar la atención en las respuestas inconscientes del sistema nervioso autónomo, lo que nos ayuda a planificar decisiones y acciones complejas.

Razón, emoción y cognición están inseparablemente entrelazadas. Y la seguridad como emoción es la base necesaria para sustentar la razón y centrar la cognición. Si para Kant la elaboración de buenos juicios morales se conseguía reforzando la razón y excluyendo la emoción, para Freud la intervención de esta era esencial en la toma de decisiones morales, y como subraya Levinas (1993: 46) "la relación de alteridad, cara a cara, es una relación ética originaria, fundante de la afectividad" y "no es solo que la emoción sea la respuesta a la razón sino que además la razón es en muchas ocasiones emocional" (Mairal Buil, 2003: 136)

Joshua Greene (2009) confirma la posición de Freud y mantiene que los dilemas morales varían en la medida en que intervienen nuestras emociones y condicionan nuestro juicio moral. Este autor propone la teoría del "proceso dual" para explicar la toma de decisiones de carácter moral. Los llamados juicios morales "utilitarios", que tienen como objetivo conseguir un bien mayor, y se sitúan por encima de los derechos individuales, se orientan por procesos cognitivos más controlados y carentes de emociones, lo que supondría la asunción de un razonamiento moral genuino. Sin embargo, los juicios morales "intuitivos" tendrían en cuenta los derechos y deberes de los individuos, lo que supone asumir unas respuestas más emocionales, cuya consecuencia es una racionalización moral interesada, que sustituye al razonamiento moral objetivo. En esta dualidad situaríamos los estudios de la seguridad como estructura relacionada con la defensa, así como la investigación antropológica de la seguridad como emoción sobre la que fundamentar nuestras decisiones.

La seguridad nos aproxima, cohesiona y fortalece, la inseguridad nos aleja, dispersa y debilita porque nos hace más vulnerables. Jerome Bruner (1974) y su escuela refuerzan la influencia del contexto y la situación para criticar la posición generalista y universal de las emociones defendida por Darwin (1998) y la adscripción de la emoción al individuo, aspecto este en el que también insisten Hutchins y Hazlehurst (1995) al plantear que lo emocional no puede situarse exclusivamente en el individuo, sino que se incorpora a partir de las prácticas culturales y los sistemas simbólicos. El sentimiento que expresamos ante una situación concreta no depende exclusivamente de la situación misma y de los 
estímulos sensoriales y químicos que nos afecten, sino de la interpretación que cada uno hace de ella según su experiencia anterior y sus expectativas futuras. Se hace por tanto necesaria la consideración de la persona como una unidad bio-socio-cultural.

Podríamos definir la seguridad como un sentimiento que se sustenta en la comprobación y la confianza. La primera responde a la dimensión cognitiva a través de la cual se incorpora la información aportada por los sentidos, lo que supone asumir el componente biológico de nuestra especie. Se situaría en el mundo visible, entendido como perceptible, puesto que existen otras realidades que no son percibidas por estar situadas fuera de los umbrales sensoriales humanos. Respecto a la confianza, se sustenta en la dimensión emocional que es gestionada culturalmente a través de la credibilidad, pero que permanece más oculta y en ocasiones difícilmente comprobable.

La inseguridad de las sociedades complejas se debe, por un lado, a que desarrollo científico y tecnológico ha trasladado nuestra percepción sensorial al mundo virtual, cuyo control lo ejercen la élites del poder, encriptando sus entornos; y por otro lado, a la crisis de credibilidad y confianza en la que nos hemos instalado, donde constata en el uso sesgado e intencionado de las palabras, lo que desde la antropología lingüística se analiza como modificaciones de la realidad. De ahí la reticencia de los políticos y demás representantes de los poderes fácticos a usar determinadas palabras que refieren a una realidad que quieren ocultar, y la adopción de otras que enmascaran esa realidad, pero que se identifican como sinónimas con el objetivo de reducir la carga emocional que la población habría atribuido a lo largo de su proceso de enculturación. En este contexto de falsificación intencionada de la realidad, han sorprendido las declaraciones del papa Francisco, que recupera términos emocionales como la vergüenza, para referirse a la tragedia de los inmigrantes que llegan a la isla de Lampedusa y las actuaciones de la Agencia de Seguridad Nacional de los Estados Unidos que ha espiado a sus aliados. No solo se desdibujan las líneas entre el "nosotros" y los "otros", sino que ya no sabemos quiénes somos "nosotros". Esta crisis de confianza nos sitúa en una crisis de identidad en la que la ausencia de seguridad, tanto para el individuo como para la comunidad refuerza su vulnerabilidad y maleabilidad. Esta crisis es mucho más grave culturalmente que la crisis de confianza atribuida a los mercados. 


\section{Seguridad personal}

Los seres humanos en tanto que seres corpóreos y mortales desarrollamos nuestra vida en referencia al complejo "cronotopo" entendido como "la unión de los elementos espaciales y temporales en un todo inteligible y concreto" (Álvarez Munárriz, 1997: 259). Para analizar la relevancia que este complejo tiene en los estudios antropológicos, es necesario asumir la definición de ser humano como ser psico-bio-físico y su incorporación dentro del "sistema complejo adaptativo" que se propone en el modelo ecosistémico, que combina las aportaciones de las ciencias de la complejidad y las ideas de G. H. Mead (2008) sobre organismo, entorno y emergencia, que se articularía tomando como base el concepto de "sistema complejo adaptativo", a través del cual podemos analizar las constricciones internas y externas que soportan las personas a lo largo del tiempo (Antón Hurtado, 2012). Asumimos el concepto de "persona" como unidad de conciencia en la que lo vivido ayer, lo experimentado hoy y lo proyectado para mañana supone la base para actuar en conciencia e incorporar nuestros propios pensamientos y sentimientos (Álvarez Munárriz, 2005: 13) confiriendo sentido a nuestra vida.

Ninguna actividad humana surge por generación espontánea, toda acción es el resultado de una planificación más o menos consciente y de la interacción que se establece con el entorno próximo o lejano. Como muy bien explicó Van Gennep (1986) al clasificar los ritos de paso, la perspectiva de continuidad temporal que estos incorporan en la vida de las personas, confiere seguridad y estabilidad a las mismas. De ahí la oportunidad de adoptar la definición de hombre como homo ritualis propuesta por Carmelo Lisón (2012), que incorporaría la definición racionalista del hombre como animal racional y la de Cassirer como animal simbólico.

Las personas nacían, crecían, se reproducían, envejecían y morían, pero esta secuencia se ha ampliado y desordenado. Los avances en biotecnología han supuesto la creación de "estados de vida latente", los embriones congelados en el inicio y la crionización en el final (Antón Hurtado, 1999). Hemos llegado a reconfigurar la potencia y el acto aristotélicos. Estamos ante una interpretación lineal del tiempo, pero como dijo Maffesoli (1993), la posmodernidad se ca- 
racteriza por una percepción cíclica del tiempo. Hemos perdido el rigor en la previsión y la planificación y nos sentimos más inseguros y vulnerables.

Los avances tecnológicos tienen como objetivo la reducción del tiempo de realización de las tareas, se trata de desplazarse más rápido, de producir más en menos tiempo, etc. Se rompe así un equilibrio fundamental que la sociedad tradicional había establecido entre tiempo y tempo. El primero se refiere al tiempo cronológico, al mensurable, mientras que el segundo está relacionado con la cadencia, la maduración, la integración, la seguridad. La humanidad ha estado sometida al cambio y a la incertidumbre desde sus orígenes, pero la gestión del tempo había facilitado la adaptación creativa a nuevos entornos. En este momento, nuestro desarrollo tecnológico, especialmente a partir de la incorporación de las tecnologías de la información y la comunicación (TIC) en nuestra vida cotidiana, han propiciado que los acontecimientos se sucedan a un ritmo vertiginoso, sin apenas tempo para la reflexión, simplemente para el acato en un ambiente de confusión. Las TIC han facilitado la formación de una nueva perspectiva temporal, el tiempo virtual que genera un "tiempo indiferenciado equivalente a la eternidad" (Castells, 1999: 499). Además, es en la red donde el juego de probabilidades y su relación con los beneficios particulares tienen su entorno de juego, pero carece de dirección en la elección, porque no existe una base de certeza en la que fundamentar las relaciones, lo que genera en sus usuarios un desasosiego, que puede derivar en vivencias ansiosas.

La sensación que podemos tener cuando nos sometemos a situaciones de gran velocidad, es, como expuso Virgilio en La Eneida, de inseguridad (Cruz, 2009), pues resulta imposible elegir una dirección, nuestro interés se centra en mantenernos dentro del sistema, porque cualquier modificación puede dejarnos fuera de él. Podemos observar en nuestros conciudadanos una parálisis motivada por la velocidad a la que se suceden los acontecimientos, por un lado, y por la situación sistémica, irracional, ininteligible, caótica y sin sentido, que estamos viviendo. La inseguridad, la inestabilidad, el miedo y la carencia de sentido son los sentimientos más frecuentes en las sociedades complejas. Como diagnostica Marc Augé (2003: 59), estamos ante una "una aceleración de la historia, de una retracción del espacio y de una individualización de los destinos".

El tiempo global resulta inaprensible y de difícil encaje cognitivo con el tiempo local y el vital, lo que genera una sensación de inseguridad, de vértigo 
al asomarnos a un agujero de gusano, de los que hablan los físicos, que supondría situarnos en un mundo paralelo, en el que no tenemos referentes para orientarnos, en el que carecemos de sentido. Un mundo repleto de estructuras de seguridad, mientras nos sentimos profundamente inseguros.

Tenemos una corporeidad que nos obliga a ocupar un espacio y este nos modifica. Se trata, por tanto, de una influencia bidireccional. Según la antropología cognitiva y, más concretamente, el cognitivismo ecológico (Gibson, 1986; Hutchins, 1995; Clark, 1997; Healy, y Braithwaite, 2000) el medio en el que desarrollamos nuestra vida, nos condiciona y modela, centrándose en procesos múltiples de ontogénesis. Paralelamente a nuestra dotación genética, nuestra corporeidad está influida por el entorno físico en el que vivimos y este es rápidamente convertido en espacio social. Para Durkheim (1993), el espacio exterior o las cosas por fuera de lo social no añaden nada a la conformación del mismo. Para Foucault (1998), una sociedad puede disciplinar a sus individuos porque anteriormente ha inscrito los cuerpos dóciles en un espacio disciplinado.

Las actividades que las personas desarrollan en los espacios aportan también otros significados, y la interpretación cultural del lugar, el sentido, se va configurando a través de una dinámica dialéctica entre los modos en que la gente entiende el lugar y las experiencias vividas en el mismo. Es por medio de esta dialéctica que un lugar llega a adquirir fuerza social (Alcock, 2001; Basso, 1996; Bradley, 1998). A lo que Marc Augé (2008) añade el sentido adscrito al lugar que suscita en las personas sentimientos de seguridad y estabilidad. Se tienen códigos de interpretación cultural para poder saber qué hacer y qué esperar. Refuerza el sentimiento de pertenencia y el de arraigo que sustentan esa sensación de seguridad. De ahí que el aumento de los no-lugares, como afirma Augé, en nuestros entornos urbanos, suponga una sensación cada vez más frecuente de extrañeza y falta de identificación con los mismos, pues aunque estética o artísticamente sean bellos, carecen de sentido en tanto significación y orientación, como para generar las sensaciones y emociones que fueron constitutivas de los lugares desde los orígenes de nuestra especie.

En el paisaje urbano, el espacio público está siendo sometido a un proceso de reducción de su sentido inicial como lugar de encuentro y sociabilidad. Loukaitou-Sideris y Banerjee (1998) mantienen que los espacios de la ciudad, sus plazas, calles, avenidas y cruces, propician unos comportamientos u otros, 
posibilitan la reunión de las diferencias humanas o las recluyen, facilitan el movimiento acelerado o el descanso. Se nos hace ver que el exterior es un lugar peligroso que debe ser vigilado a través de innumerables cámaras de seguridad instaladas en las calles y plazas de nuestras ciudades. A la "reducción del espacio" propuesta por Augé habría que añadir la "aceleración del tiempo" referida más arriba. En palabras de David Harvey (2011) asistimos a un "ajuste espacio-temporal" que genera en las personas estados de ansiedad, inseguridad, vulnerabilidad y desasosiego por la carencia de sentido.

\section{Seguridad comunitaria}

Considero la propuesta de Luis Álvarez Munárriz (2011b: 80) de los cuatro módulos de la cultura, el tecno-económico, el institucional, el ideal y el paisaje, como el modelo más operativo para analizar la percepción social de la seguridad.

Respecto al primero de los módulos, parece oportuna la distinción entre sociedad industrial y sociedad del riesgo que establece Beck (2010), cuya separación puede hacerse atendiendo a dos criterios fundamentales: 1) según la distribución de bienes -en el caso de la sociedad industrial-y de estos unidos a males o peligros en la sociedad del riesgo y 2) según la estructura social, pues mientras la primera se organiza en base a la clase social, la segunda lo hace teniendo como referente al individuo. Así pues, la sociedad del riesgo es la sociedad industrial en la que el individuo toma conciencia del peligro que puede suponer la implantación de determinados descubrimientos científicos y tecnológicos. Estos avances son cada vez más difíciles de decodificar por la celeridad con la que se suceden, que sitúan al individuo ante un déficit cognitivo o lo que es igual: mucha información y poca comprensión; a lo que habría que añadir la cuestionable veracidad de la información a la que accedemos debido a la manipulación semántica intencionada con la que la transmiten y el uso que los poderes fácticos hacen de esa información, generando una sensación de control, desconfianza, inseguridad y vulnerabilidad.

La "revolución genómica" ha situado a los individuos de las sociedades complejas entre la esperanza y la inseguridad. Se pensaba que las investigacio- 
nes biotecnológicas iban a propiciar la erradicación de numerosas enfermedades, la sustitución de órganos y tejidos dañados sin sufrir rechazo, la eliminación de la esterilidad y del hambre, etc.; pero se constata que estas biotecnologías no llegan a la mayoría de la población mundial, que no tiene suficiente poder adquisitivo para contratarlas. Además, son tecnologías ambiguas que en ocasiones generan alarma social en la población debido a la manipulación de los alimentos y las consecuencias para la salud de las personas, lo que ha generado una desconfianza en las estructuras de la seguridad alimentaria que son incapaces de detectar prácticas de riesgo que responden más a intereses empresariales que al bien común. La erradicación del hambre forma parte de los Objetivos del Milenio de la ONU, pero estamos lejos de conseguirlo debido a la especulación que determinadas empresas alimentarias y entornos financieros promueven. Simultáneamente se teme por el mal uso que se pueda hacer de la clonación, con la posibilidad de propiciar una eugenesia racial, la distorsión de la identidad personal, la reducción de la biodiversidad, la aparición de nuevos gérmenes, el aumento de las alergias y las intolerancias etc.

La "revolución digital" modifica las relaciones sociales generando una saturación de las relaciones virtuales y una reducción de las interpersonales, además de modificaciones en el sistema cognitivo por la incorporación de estas nuevas tecnologías.

La civilización altamente tecnológica, el Estado del bienestar, el mercado mundial, la esfera de los media: todos esos grandes proyectos quieren imitar en una época descascarada la antigua seguridad de las esferas, pero esta se ha vuelto imposible. Ahora el ser humano tiene que procurarse redes y pólizas de seguros que han de ocupar el lugar de los caparazones celestes; la telecomunicación debe imitar lo envolvente. El cuerpo de la humanidad quiere procurarse un nuevo estado de inhumanidad dentro de una piel electrónico-mediática (Vásquez Rocca, 2008).

La desconfianza se ha instalado incluso entre los que se consideran aliados, como se ha podido comprobar a partir del espionaje masivo de los servicios secretos de los Estados Unidos. La seguridad se diluye en los entornos virtuales, en los que se genera incertidumbre y aislamiento, solo superado por el individuo si accede al ámbito de la realidad, lo que puede suponer desilusión y 
riesgo. Los medios de comunicación de masas llevan a cabo una saturación del espectador con imágenes de sufrimiento, cuya presencia frecuente consiguen una habituación a la misma que se refleja en una frialdad emocional y su consiguiente deshumanización. Por otro lado, en esta sociedad el conocimiento se divulga con rapidez debido a la instantaneidad de la información en los entornos virtuales y la rentabilidad económica que supone lo novedoso en el mercado, pero no siempre ese conocimiento se ha falseado convenientemente, de ahí que la divulgación de información contradictoria y la continua revisión de los contenidos genere en el individuo una sensación de inseguridad.

Las causas de la crisis económica actual no es una quiebra en el sistema productivo es una estafa del sistema especulativo porque ya no interesa prever para proveer, sino prever para especular. Esta situación es vivenciada por nuestros conciudadanos con una sensación de miedo, inseguridad, incomprensión, injusticia y vulnerabilidad que dificulta la reacción ante una crisis que es global, multifacética y está sincronizada (Tortosa, 2010).

El segundo módulo de cultura es el institucional, que regula esa necesidad de la especie humana de vivir en sociedad. Nuestra sociabilidad la desplegamos en tres grandes niveles y uno de ellos es el micro, donde situamos a la familia, que está en continua redefinición para desplegar su gran potencial adaptativo tanto a través de sus miembros como de las relaciones que se establecen entre ellos y las respuestas que se requieren para superar los retos del entorno.

En la sociedad patriarcal, la estabilidad familiar se basaba en la indisolubilidad del matrimonio, era la pareja con fines procreativos la que garantizaba la seguridad emocional de sus miembros. La forma de expresar las emociones depende en gran medida del proceso de socialización recibido, de tal forma que los niños se van integrando en las actividades y los mundos comprensivos de los adultos (Lutz, 1983) a través de la educación de las emociones que reciben en sus entornos familiares y socioculturales. Pero con la educación de las emociones no solo se consigue reforzar los procesos cognitivos que fijan la experiencia a partir de la memoria, sino que -como plantea la teoría del vínculo (Bowlby, 1969; Ainsworth et al., 1974)- el afecto que despliegan los padres hacia sus hijos supone para los bebés una plataforma de seguridad emocional que les permite desarrollar en mayor medida su curiosidad y capacidades exploratorias. 
Los cachorros humanos aprenden a interpretar la expresión de las emociones de su madre o cuidador en su proceso de crecimiento y enculturación. A partir del segundo año de vida ya han establecido la relación entre emoción, cognición y comportamiento de tal forma que ya son capaces de provocar emociones en las personas de su entorno más próximo y a partir del tercer año manifiestan un mayor interés por el estado emocional de los demás (Dunn, 1988). Bates (1979) insiste en que la resolución de tareas, el aprendizaje y la empatía (en tanto que detección y participación en estados emocionales) están presentes, desde el punto de vista ontogenético, en los niños normales, de ahí que los niños autistas manifiestan una incompetencia social debida a la ausencia de destrezas comunicativas y de "pretensión" (intención de provocar emociones en los demás) (Baron-Cohen, 1991).

A lo largo del siglo pasado han ido apareciendo otros modelos de familia y se viene observando un refuerzo de las relaciones materno, paterno-filiales en detrimento de la pareja patriarcal. Esta intensificación de la filiación tiene especial relevancia en las relaciones materno-filiales y suponen una actualización de los lazos afectivos primigenios que nuestra especie estableció desde los albores de la misma. La maternidad es una relación biológica y visible para el individuo y la comunidad, la paternidad, por el contrario, es social y no ha tenido medio de confirmación hasta los años 90 del pasado siglo, con las pruebas de ADN. La poliparentalidad que el desarrollo biotecnológico ha propiciado a través de la técnicas de reproducción asistida con donante ha supuesto una combinación de lo visible con lo invisible. La ley de reproducción asistida garantiza el anonimato a los donantes del material genético, lo que supone su invisibilidad física y su ausencia emocional, instalando así un sentimiento de inseguridad en numerosas familias que recurren a estas técnicas.

La sociedad actual genera "el aislamiento del individuo, que no se identifica con las organizaciones burocráticas centralizadas y busca en las organizaciones independientes (tanto religiosas como sociales y políticas) comunidades locales y asociaciones voluntarias, en las que recuperar formas de integración y de solidaridad" (Antón Hurtado, 1996: 226). Ante la amenaza y los riesgos de la sociedad posmoderna -o como dice Habermas (1985): la "colonización del mundo vital por el sistema"- el individuo desarrolla una "unidad negativa" incorporándose a pequeños grupos, tanto sociales como religiosos, en los que 
se llevan a cabo procesos de atribución colectiva de sentido. Los nuevos movimientos sociales (NMS)

Pretenden recuperar para el ámbito de la opinión y la discusión públicas problemas ambientales, energéticos, de discriminación o de defensa nacional, confinados en la categoría de cuestiones técnicas por el discurso oficial [...]. Los NMS tratan de desarrollar, por tanto, una nueva cultura de la política, una ampliación del espacio político y del ámbito de responsabilidad ciudadana (la política no institucional de Offe), como tercer ámbito entre lo privado y lo público-político (Sosa, 1997: 280).

La frustración, el sufrimiento y el sentimiento de impotencia, al no poder resolver las paradojas éticas que se plantea la sociedad actual, son elementos decisivos a la hora de integrarse en los nuevos movimientos religiosos (NMR). El aspecto religioso del sufrimiento no es cómo evitarlo, sino cómo hacerlo soportable (Geertz, 1972). "En estos nuevos grupos, los sufrimientos individuales y colectivos se desparticularizan, permitiendo misteriosos coloquios que tiene una función terapéutica y restituyen la sociabilidad" (Antón Hurtado, 1996: 229).

Como dice Ulrich Beck (2003: 40) "el capitalismo global amenaza la cultura de la libertad democrática al radicalizar las desigualdades sociales y al revocar los principios de la seguridad y la justicia social". Si asumimos una visión diacrónica de la situación, la conquista del fuego tuvo una aplicación clara en la defensa de la comunidad frente a los ataques de los animales, lo que reforzó el sentimiento de seguridad. El desarrollo de las primeras herramientas también pone de manifiesto el interés de nuestros antepasados por garantizar la seguridad de los miembros del grupo a través de las estrategias de defensa. Esta consideración de la defensa como estructura para garantizar la seguridad se ha transmitido hasta la actualidad, pero la novedad de este momento se sitúa en la gestión de la misma.

Resulta paradójico que la modernidad, a través de la implantación del "Estado del bienestar", se afanara en minimizar los peligros que atemorizaban a los individuos estableciendo una serie de sistemas de seguridad social, incorporando avances tecnológicos al ámbito sanitario, posibilitando el acceso a la educación, regulando los entornos del trabajo a través de los derechos laborales 
y los convenios colectivos, estableciendo mecanismos de control financiero y los ciudadanos modernos nos sentimos más vulnerables e inseguros que nunca. Se pretendía proteger a las personas de accidentes y calamidades, favoreciendo un clima de confianza y bienestar que consiguiera disminuir la angustia y el miedo. Sin embargo, pese al elevado nivel de eficiencia de las instituciones públicas y las tecnologías modernas, los Gobiernos liberales de Thatcher y Reagan, durante la década de los años 80, proponen recortar gastos del Estado (generalmente sociales), privatizar empresas públicas para sanear las arcas del Estado, debilitar el movimiento sindical para flexibilizar el mercado laboral y desregular las entidades financieras. Estas medidas se aumentan y radicalizan a partir de la crisis de 2008 cuando los Estados "democráticos" se convierten en agentes proactivos que adaptan el marco legal a los dictámenes que les marca el gran capital financiero y especulativo, que con una rapidez inusitada va concentrando más poder.

La usurpación del Estado por parte del mercado es fuente de incertidumbre y miedo, que junto con la desregulación, la flexibilidad y la competitividad sumergen a los individuos en sensaciones de aislamiento y desamparo que nos hacen más vulnerables (Bauman, 2003a). El aislamiento prolongado conlleva la pérdida de la seguridad personal y la reducción de las capacidades afectivas, provocando en la sociedad lo que Salazar Pérez (2011: 32) llama "autismo social", que se manifiesta en la falta de interés por el otro, situándonos en un "sálvese quien pueda" y anulando toda posibilidad de ejecutar una acción colectiva. La gestión de la crisis actual por parte de los poderes económicos y políticos está fracturando la sociedad hasta atomizarla, "insularizarla" e insensibilizarla, para anular cualquier posibilidad de reacción empática colectiva.

El Estado-nación y las organizaciones supranacionales coexisten, pero sin referencias claras. "La superación del Estado-nación (pieza clave en la geometría política de la historia moderna) por instancias de poder supranacionales conllevan el vaciamiento del espacio político clásico" (Jarauta, 2010: 19). Durante la Guerra Fría, la estrategia de seguridad se concretaba en organizaciones de defensa como la OTAN, que actuaría ante un hipotético ataque enemigo de la URSS. Tras la caída del Muro de Berlín, la nueva situación geopolítica del planeta y la implantación del sistema económico neoliberal se ha reinterpretado el fundamento inicial de la estructura de seguridad. Ya no se trata de 
organizarse para defenderse, puesto que la localización del ataque es difusa. El terrorismo internacional ha puesto de manifiesto que no resulta fácil garantizar la seguridad de los ciudadanos a través de la estructura de defensa de los Estados ni de las "intervenciones militares" de las organizaciones internacionales. Las instituciones públicas, en el nuevo contexto socioeconómico globalizado, no pueden asumir los costes de las estructuras de seguridad, lo que tiene como consecuencia la privatización de los mismos a través de empresas de seguridad -en el ámbito visible- y de organizaciones criminales -en lo invisible. En estos dos entornos, el objetivo de la defensa ya no se sitúa en garantizar la seguridad de las personas para el desarrollo de un proyecto de vida satisfactorio, más bien al contrario, potenciar el sentimiento de temor e inseguridad, para que a través de la vulnerabilidad del individuo y su aislamiento, se puedan conseguir pingües beneficios económicos.

La sociedad del riesgo de Beck (2010) se fundamenta en la combinación de dos factores, la ausencia de mediaciones políticas frente a la complejidad de los nuevos conflictos que plantea la globalización y la generalización de un modelo administrativo del mundo, gestionado desde un sistema de intereses elitista, ajeno al referente moral de la historia que había orientado la tradición moderna.

La aparición de nuevos agentes económicos y financieros capaces de supeditar a la lógica de sus intereses las decisiones de los poderes políticos ha problematizado una vez más la autonomía de lo político, para dar lugar a nuevas formas de dependencia que podemos observar a nivel planetario. Se trata de una crisis de lo político que adquiere una relevancia todavía mayor cuando las decisiones acerca de la parte de la humanidad más desfavorecida se ven cautivas de intereses económicos, regidos por criterios ajenos a la defensa del bien común (Jarauta, 2010: 19).

El descrédito de los políticos en España, por ejemplo, se justifica por la falta de credibilidad de sus propuestas y por la desconfianza de sus actuaciones. En dos generaciones se ha pasado del valor de la palabra dada a la negación de la palabra escrita, contraviniendo los términos evangélicos de "lo escrito, escrito está" como garantía de seguridad. Se observa en la clase política un absoluto desprecio a la ciudadanía cuando se les interpela por lo dicho y no responden, violando así los principios más básicos del respeto no solo a las instituciones, 
sino al "otro" como interlocutor. La mentira, la opacidad, los intereses inconfesables, la confusión intencionada, se han instalado con naturalidad en los entornos políticos.

El módulo ideal concentraría las creencias, los valores y las normas que actúan como catalizadores de sentido para las personas que las asumen como referencia, pero en las sociedades complejas actuales las creencias son difusas, los valores están eclipsados por el valor hegemónico del dinero y las normas han disociado o contrapuesto legalidad y justicia

A través del relato, sea mítico o racional, se consigue reorganizar los hechos y educar las emociones. Los mitos ordenaban la realidad, la hacían inteligible ya que aportaban una explicación de la misma y justificaban un orden del mundo a partir de la transmisión de unos valores. Bruno Bettelheim (1994) distingue dos tipos de cuentos, según el entorno sociocultural en el que transitan: 1) el mito trágico es característico de sociedades estratificadas y tendría como expresión más relevante los relatos bíblicos y 2) el cuento popular tradicional sería propio de sociedades dinámicas que manifiestan una aptitud más optimista ante la vida. El relato en la situación actual de crisis se ha vuelto ininteligible y falto de veracidad, por eso ya no resulta explicativo ni justifica el orden impuesto. Las explicaciones que se ofrecen son confusas, contradicen los hechos, refuerzan la incomprensión, y como consecuencia aumentan la inseguridad. El relato racional ha abandonado el ámbito colectivo para buscar refugio en lo personal.

Asumo la consideración del hombre como homo ritualis y la definición de rito propuesta por Carmelo Lisón, según la cual

El rito es un universal cultural presente en todas las culturas y en su complejidad refracta dimensiones plurales de lo humano que le otorgan un carácter misterioso y de difícil comprensión. El rito es inseparable de momentos importantes de transición en el ciclo de la vida y se acompaña de ritmo, danza, canto, melodía, música, himnos, percusión, banderas, emblemas, iconos, luminaria, color, hábitos y estética. El rito significa, vehicula sentido, significado y sentido que pródigamente expresan y simbolizan, significado y sentido que requieren de interpretación hermenéutica [y a través de la analogía que se establece en los procesos rituales, pretende] por una parte, ordenar desde un ángulo cognitivosimbólico el universo entero y, por otra, al pasar el contenido a registro mágicoritual, persuadir, convencer, lograr efecto (Lisón, 2012: 22, 28). 
Además, el rito transmite información sobre los participantes, expresa valores, reafirma y mantiene las relaciones de los miembros de la comunidad y restaura el equilibrio tras situaciones de crisis, porque la participación en el mismo condensa emoción. "La conciencia de que esta colectividad existe y la conciencia de formar parte de ella contribuyen a la emoción que suscita y, eventualmente, a la confianza que conlleva" (Augé, 2004: 98). Los ritos como catalizadores de emoción, y especialmente, los de paso a través de la etapa de agregación, proporcionaban seguridad al individuo y a la comunidad, la sociedad compleja los ha reorientado hacia el consumo, hasta tal punto que nos ha hecho sentir que solo la adquisición de bienes y servicios, los más innovadores y caros que nos podamos permitir, serían los garantes del acceso a esa seguridad conquistada por la participación de los seres humanos en el ritual. Esta participación se ha vaciado de sentido y se ha focalizado al reconocimiento social que supone su valoración dentro de la sociedad de consumo. Los ritos de paso tradicionales se han reinterpretado con vistas al reconocimiento social del poder adquisitivo que los participantes muestran en las celebraciones.

Las creencias y los valores de la sociedad actual se identifican, en gran medida, con los principios de la "poseconomía". Existe una creencia férrea en el progreso económico ilimitado, sin tener en consideración las repercusiones tanto humanas como medioambientales que genera. Se vehicula la creencia en la felicidad a través del fomento del consumo, que solo es posible con el dinero como valor hegemónico. La valoración del enriquecimiento rápido a través de los "pelotazos urbanísticos" y otros negocios moralmente reprobables y la filosofía del "usar y tirar" son una manifestación de las creencias "posmaterialistas".

Respecto a las normas comparto la afirmación de Alexy (2004: 21) de que "el conjunto de leyes de una sociedad, positivamente formuladas, no es todo el derecho de las personas, sino la concreción de la limitación de algunos derechos que los socios ponen en común; limitación que mutuamente respetarán para un mejor ejercicio de los propios derechos, en particular del uso moral de la libertad, la cual es el origen de todos los derechos de las personas" En consecuencia, si, lejos de proteger la libertad, es el propio Estado el que impide su ejercicio, habilita ámbitos de impunidad policial, colabora a través de los servicios secretos en las detenciones ilegales y torturas practicadas por sus fun- 
cionarios, tal es el caso de Estados Unidos en el territorio de la Unión Europea. La fórmula parece clara: "a mayor seguridad, menor libertad".

\section{Seguridad planetaria}

Como dice Giddens (2000: 38), los seres humanos siempre hemos estado expuestos a riesgos naturales tradicionales, las catástrofes medioambientales, por ejemplo, pero los actuales son "riesgos manufacturados", asociados a las nuevas tecnologías y al terrorismo, que fomentan la inestabilidad de la vida contemporánea y el nerviosismo característico de la civilización occidental contemporánea.

El éxito de la especie humana habría que situarlo en la adquisición de una cultura que facilita nuestra transformación creativa de los entornos inestables, con frecuencia adversos y en ocasiones hostiles. Siempre hemos buscado hacer seguro lo inseguro, los seres humanos gestionamos muy mal la incertidumbre y el caos, pero la singularidad del momento actual es que la inseguridad se ha hecho planetaria tanto desde el punto de vista socio-físico (riesgo ecológico, riesgo nuclear, riesgo genético, etc.), como desde el punto de vista cultural (consumismo y estilo de vida insostenible). Ya en el Informe Brundtland (1987) se animaba a las personas, a las organizaciones civiles y a los educadores a que establecieran en los entornos educativos la vinculación entre los problemas ambientales y los cambios sociales que serían necesarios para corregir el rumbo del desarrollo. En este contexto debemos concienciarnos que todos dependemos de todos $\mathrm{y}$, en consecuencia, reconocer que la complejidad de los problemas que enfrenta la humanidad solo se pueden resolver en un contexto global.

En la actualidad, la seguridad de las personas pasa por la cooperación de todos los habitantes del planeta Tierra y aunque los "señores poseconómicos" puedan prescindir del 99\% de los habitantes, "pasen de política", se paseen en sus jets privados, habiten sus propias islas y se refugien en sus bunkers, siguen siendo corpóreos y la amenaza del riesgo ambiental es colectiva. En esta situación, la perspectiva antropológica nos indica la necesidad de que las personas se comprometan con la cultura del lugar que habitan, así como a resaltar la relación dialéctica entre los hombres y su mundo circundante. 
En su trabajo de campo, el antropólogo pretende conocer el mapa mental, el significado y el modo cómo las personas han configurado y desean configurar el territorio que habitan. Se interesa por los referentes simbólicos del espacio en el que viven, que valor le otorgan y que normas quieren fijar para conservarlos o recrearlos. Sus aportaciones ayudan a la gente a que vea el territorio no solamente desde un punto de vista económico, como fuente de recursos, sino también como espacio físico que contribuye a aumentar el bienestar y la calidad de vida de las personas, es decir, como paisaje. Nos encontramos ante un reto que concierne a todos los habitantes del planeta y en el que todos estamos comprometidos.

\section{Bibliografía}

Ainsworth, M. D., Bell, S. M. y Stayton, D. J.

1974 "Infant-mother attachment and social development: socialisation as a product of reciprocal responsiveness to signals". En: Richards, M.P. (ed.), The integration of a child into a social world. Cambridge: CUP.

Alcock, S. E.

2001 "The reconfiguration of memory in the eastern Roman Empire". En: Alcock, S. E. et al. (eds.), Empires. Cambridge: Cambridge University Press.

Alexy, R.

2004 El concepto y la validez del derecho. Barcelona: Gedisa.

Álvarez Munárriz, L.

1997 “Tercer milenio: tiempo de utopía”. En: Anales de la Fundación Joaquín Costa. $\mathrm{N}^{\mathrm{o}} 14$.

Álvarez Munárriz, L.

2005 "La conciencia humana”. En: Álvarez Munárriz, L. (ed.), La conciencia humana: perspectiva cultural. Barcelona: Anthropos.

Álvarez Munárriz, L.

2011a "La compleja identidad personal". En: Revista de Dialectología y Tradiciones Populares. Vol. LXVI. No 2.

Álvarez Munárriz, L.

2011 b "La categoría de paisaje cultural". AIBR, 6/1. 
Álvarez Munárriz, L.

2013 "Prólogo". En: Antón Hurtado, F. y Ercolani, G. (eds.), Anthropology and Security Studies. Murcia: Universidad de Murcia. Disponible en: http:// diegomarin.net/umu/en/sociologia-y-antropologia/133-anthropology-andsecurity-studies-9788416038008.html [20 de mayo de 2013].

Antón Hurtado, F.

1996 "Producción de sentido en los nuevos movimientos religiosos". En: Sociedad y Utopía. Revista de Ciencias Sociales. № 8.

Antón Hurtado, F.

1999 "Sensibilización social ante el reto de la biotecnología”. En: Álvarez Munárriz, L. y Guerrero Muñoz, J. (eds.), Biotecnología y familia. Factores socioculturales y éticos. Murcia: DM.

Antón Hurtado, F.

2012 “Antropología del Sinsentido". En: Revista de Antropología Experimental. $\mathrm{N}^{\circ}$ 12. Disponible en: http://www.ujaen.es/huesped/rae/articulos2012/27anton 12.pdf [15 de mayo de 2013].

Antón Hurtado, F. y Ercolani, G. (eds.)

2013 "Introduction". En: Anthropology and Security Studies. Murcia: Universidad de Murcia. Disponible en: http://diegomarin.net/umu/en/sociologia-yantropologia/133-anthropology-and-security-studies-9788416038008.html [24 de mayo de 2013].

Arsuaga, J. L. y Martín-Loeches, M.

2013 El sello indeleble. Pasado presente y futuro del ser humano. Barcelona: Debate.

Augé, M.

2003 El tiempo en ruinas. Barcelona: Gedisa.

Augé, M.

2004 ¿Por qué vivimos? Por una antropología de los fines. Barcelona: Gedisa.

Augé, M.

2008 Los no lugares, espacio del anonimato: una antropología de la sobremodernidad. Barcelona: Gedisa.

Baron-Cohen, S.

1991 "Do people with autism understand what causes emotion?". En: Child Development. $\mathrm{N}^{\mathrm{o}} 62$.

Barrie, J. M.

1992 Peter Pan. Madrid: Alianza. 
Basso, K. H.

1996 "Wisdom sits in places: Notes on a western Apache landscape". En: Feld, S. y Basso, K. H. (eds.), Senses of Place. Santa Fe: School of American Research Press.

Bates, E. et al.

1979 The Emergence of symbols. Cognition and Communication in Infancy. Nueva York: Academic Press.

Bauman, Z.

2003a Comunidad. En busca de seguridad en un mundo hostil. Madrid: Siglo XXI. Bauman, Z.

2009 Amor líquido: acerca de la fragilidad de los vínculos humanos. Madrid: FCE.

Beck, U.

2003 Sobre el terrorismo y la guerra. Barcelona: Paidós.

Beck, U.

2010 La sociedad del riesgo: hacia una nueva modernidad. Barcelona: Paidós.

Benedict, R.

1934 “Anthropology ang the Abnormal”. En: Psychol. № 10.

Benedict, R.

1974 [1946] El crisantemo y la espada: patrones de la cultura japonesa. Madrid: Alianza.

Bettelheim, B.

1994 [1975] Psicoanálisis de los cuentos de hadas. Barcelona: Crítica.

Boas, F.

1992 [1911] La mentalidad del hombre primitivo. Buenos Aires: Almagesto.

Bowlby, R.

1969 Attachment and Loss. Vol. 1. Attachment. Londres: Hogarth Press.

Bradley, R.

1998 The Significance of Monuments: On the Shaping of Human Experience in Neolithic and Bronze Age Europe. London: Routledge Press.

Bruner, J.

1974 “The organization of early skilled action”. En: Richards, M. P. M. (ed.), The integration of a child into a social world. Cambridge: CUP.

Castells, M.

1999 La era de la información. Economía, sociedad y cultura. Madrid: Alianza.

Chudnovsky, E. y Tejada, J.

2011 El viaje de Cloe. Barcelona: Destino 
Clark, A.

1997 Being There: Putting Brain and World Together Again. Cambridge y Massachusetts: The MIT Press.

Cruz, N.

2009 "La Eneida, Virgilio y Eneas”. Disponible en: http://www.historiaycultura. cl/doc/Virgilio\%20y\%20la\%20Eneida/Eneida_Virgilio_Eneas.pdf [15 de mayo de 2013].

Darwin, Ch.

1998 [1872] La expresión de las emociones en los animales y en el hombre. Madrid: Alianza.

De Pina Cabral, J.

2003 "La ficción como exutorio". En: Lisón, C. (ed.), Antropología: horizontes emotivos. Granada: Universidad de Granada.

Deleuze, G. y Parnet, C.

1997 Diálogos. Valencia: PreTextos.

Dunn, J.

1988 The Beginnings of Social Understanding. Oxford: Basil Blackwell.

Durkheim, E.

1992 [1912] Las formas elementales de la vida religiosa. Madrid: Akal.

Durkheim, E. y Mauss, M.

1963 Primitive Classification. Londres: Cohen \& West.

Favret-Saada

1994 “Weber, les émotions et la religión”. En: Terrain. № 22.

Fericgla, J. M.

2012 "Cultura y emociones. Manifiesto por una Antropología de las emociones". Disponible en: http://web.usal.es/ meilan/LA\%20RISA\%20CD/mundorisa/ risauniversal/Antropologia.htm [12 de octubre de 2013].

Foucault, M.

1998 Vigilar y castigar. Madrid: Siglo XXI.

Freud, S.

1972 [1915] "Lo inconsciente”. En: Obras completas. Vol. VI. Madrid: Biblioteca Nueva.

Geertz, C.

1972 “La religion comme système culturel”. En: Essais d'anthropologie religieuse. París: Gallimard.

Geertz, C.

1973 The Interpretation of Culture. Nueva York: Basic Book. 
Giddens, A.

2000 Un mundo desbocado. Los efectos de la globalización en nuestras vidas. Madrid: Taurus.

Greene, J.

2009 "Dual.process morality and the personal/impersonal distinction: A reply to Maguire, Langdon, Coltheart, and Mackenzie”. En: Journal of Experimental Social Psychology. Vol. 45. № 3 .

Habermas, J.

1985 Conciencia moral y acción comunicativa. Barcelona: Península.

Harvey, D.

2011 The enigma of capital and the crisis of capitalism. Oxford: Oxford University Press.

Healy, S. y Braithwaite, V.

2000 “Cognitive ecology: a field of substance?”. En: Trends Ecol. Evol. № 15.

Hutchins, E.

1995 Cognition in the Wild. Cambridge y Massachusetts: The MIT Press.

Jarauta, F.

2010 "El futuro de Europa". Lección inaugural del curso académico 2010-2011 en las Universidades Públicas de la Región de Murcia. 17 de septiembre de 2010.

Hutchins, E. y Hazlehurst, B.

1995 "How to invent a shared lexicon: the emergence ofshared form meaning mappings in interaction". En: Goody, E. (ed.), Social Intelligence and Interaction. Expressions and Implications of the social bias in human intelligence.

Kandel, E. R.

2013 La era del inconsciente. Barcelona: Paidós.

Lévi-Strauss, C.

2011 L'anthropologie face aux problèmes du monde modern. Paris: Seuil.

Levinas, E.

1993 [1974] Humanismo del Otro Hombre. Madrid: Caparrós.

Lisón, C.

2012 "Rito, funciones y significado". En: Música oral del Sur: Música hispana y ritual. $\mathrm{N}^{\circ} 9$.

Loukaitou-Sideris, A. y Banerjee, T.

1998 Urban Design Dowtown: Poetics and Politicis of Form. Berkley: University of California Press. 
Lutz, C.

1983 "Parental Goals, Ethnopsychology and the Development of Emotional Meaning”. En: Ethos. N ${ }^{\circ} 11(4)$.

Maffesoli, M.

1993 La contemplation du monde. Figures du style communautaire. París: Bernard Grasset.

\section{Mairal Buil, Gaspar}

2003 “Discursos de riesgo y agonía". En: Lisón, C. (ed.), Antropología: horizontes emotivos. Granada: Universidad de Granada.

Mauss, $\mathrm{M}$.

1991 [1968] Sociología y Antropología. Madrid: Tecnos.

Mead, G. H.

2008 [1931] Filosofia del presente. Madrid: CIS.

Peristiany, J. G. (comp.

1968 El concepto de honor en la sociedad mediterránea. Barcelona: Labor.

Salazar Pérez, R.

2011 "Los miedos ocultos en la sociedad del siglo XXI". En: Theomai. № 23, pp. 24-34.

Shilling, C. y Mellor, P.

1996 "Embodiment, structuration theory and modernity: mind/body dualism and the repression of sensuality". En: Body \& Society. No 2(4).

Sosa, N. M.

1997 "Ética ecológica y movimientos sociales". En: Sociedad y medio ambiente. Madrid: Trotta.

Thacker, T.

2010 Joseph Goebbles: vida y muerte. Barcelona: Ariel.

Tortosa, J. M.

2010 "Estado y Estado de bienestar: coyuntura y perspectivas de futuro". En: Daímon. Revista Internacional de Filosofia. № 51.

Tourain, A.

2011 "Plus personne en contrôle personne". En: Revue de deux mondes.

Van Gennep, A.

1986 Ritos de paso. Madrid: Taurus.

Vásquez Rocca, A.

2008a "Peter Sloterdijk: espacio tanatológico, duelo esférico y disposición melancólica”. En: Nómadas. Revista Crítica de Ciencias Sociales y Jurídicas. № 
17. Disponible en: http://pendientedemigracion.ucm.es/info/nomadas/17/ avrocca_sloterddijk2.pdf [14 de septiembre de 2013].

Vásquez Rocca, A.

2008 b"Individualismo, modernidad líquida y terrorismo hipermoderno; de Bauman a Sloterdijk”. En: Konvergencias, Filosofía y Culturas en Diálogo. Año V. No 17. Disponible en: http://www.konvergencias.net/vasquezrocca168. pdf [16 de julio de 2013].

Yuri, I. y Mikko, E.

2005 "Emotion and Consciousness: Ends of a Continuum". En: Cognitive Brain Research. $\mathrm{N}^{\mathrm{o}} 25$.

Envío 29 de octubre/2013 - Aceptación 17 de diciembre/2013 